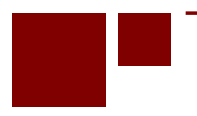

C E N T E R for RETIREMENT RES E A R C H at BOSTON COLLEGE

\title{
RECRUITING AND RETAINING HIGH-QUALITY STATE AND LOCAL WORKERS: DO PENSIONS MATTER?
}

\author{
Alicia H. Munnell, Jean-Pierre Aubry, and Geoffrey T. Sanzenbacher \\ CRR WP 2015-1 \\ Released: January 2015 \\ Center for Retirement Research at Boston College \\ Hovey House \\ 140 Commonwealth Avenue \\ Chestnut Hill, MA 02467 \\ Tel: 617-552-1762 Fax: 617-552-0191 \\ http://crr.bc.edu
}

All the authors are affiliated with the Center for Retirement Research at Boston College (CRR). Alicia H. Munnell is the Peter F. Drucker Professor of Management Sciences at Boston College's Carroll School of Management and the director of the CRR. Jean-Pierre Aubry is the assistant director of state and local research at the CRR. Geoffrey T. Sanzenbacher is a research economist at CRR. The findings and conclusions expressed are solely those of the authors and do not represent the views of Boston College. The authors thank Joe Prestine for help collecting and advice on working with the PPD data and Christine Manuelo for help collecting the PPD data. The authors also thank Mark Rider and participants of the National Tax Association Annual Conference for helpful comments. Any errors are their own.

(C) 2015, Alicia H. Munnell, Jean-Pierre Aubry and Geoffrey T. Sanzenbacher. All rights reserved. Short sections of text, not to exceed two paragraphs, may be quoted without explicit permission provided that full credit, including $₫$ notice, is given to the source. 


\begin{abstract}
Many state and local governments have responded to challenges facing their pension plans by cutting benefits. Will these cuts make it harder for state and local governments to recruit and retain high-quality workers? To date, the answer has been difficult to obtain; most micro-level datasets contain information on the existence of pensions but not on pension generosity. To get around this constraint, this study uses a unique source, the Public Plans Database, to obtain data on the pension generosity of state and local workers' pensions. These data are merged with the Current Population Survey to investigate how pension generosity affects the gap between the private sector wage of workers that states and localities recruit from the private sector relative to the workers that they lose to it. The findings suggest relatively generous pensions help reduce this “quality gap,” making it easier for state and local employers to recruit high-earning workers from the private sector and retain those workers. The effect is similar regardless of whether employer or employee contributions finance the benefits. The study suggests states should be cautious as they cut their pension benefits and that a strategy to maintain benefits by shifting some costs onto employees may help maintain states' ability to recruit and retain high-quality workers.
\end{abstract}




\section{Introduction}

Many state and local governments have responded to challenges facing their pension plans by cutting benefits, typically for new employees. These reductions range from increases in age and tenure requirements for benefit receipt to reductions in cost-of-living adjustments (COLAs). In the long run, these benefit reductions will reduce a component of public employment compensation - public pensions - that helps ensure comparability of total compensation between the private and public sectors. ${ }^{1}$ But, even if total compensation were held constant through future wage increases, will these reductions in pensions have an impact on state and local governments' ability to recruit and retain high-quality workers in competition with the private sector? The answer is unclear. Numerous studies have documented that the existence of an employer pension reduces worker quits and that people who value pensions are higher-quality workers. ${ }^{2}$ Virtually no studies have examined what role, if any, pension generosity plays regarding the quality of workers recruited and retained by employers. ${ }^{3}$ The practical effect of this is that as states and localities reduce the generosity of their pensions, they have little information about how these cuts will affect their ability to recruit and retain high-quality workers will change.

In large part, the lack of research in this area is due to a lack of data. While most widely available micro-datasets ask questions regarding the availability of a pension, they rarely provide information about its structure or generosity. ${ }^{4}$ Since states are not eliminating their pensions, but rather reducing benefit generosity, studies relying on the existence of a pension may not have much to say about the issue at hand.

This study attempts to fill some of the gaps in our knowledge by examining the relationship between the generosity of state and local pensions and the quality of workers entering and exiting the state and local sector. To accomplish this goal, the study obtains two things: 1) a measure of pension generosity; and 2) a measure of worker quality. For the first, the analysis takes advantage of a unique data set, the Public Plans Database (PPD) maintained by

\footnotetext{
${ }^{1}$ Munnell, Aubry, Hurwitz, and Quinby (2011) find that once pensions are accounted for, state and local employees receive slightly less in total compensation than their private sector counterparts, whereas Richwine and Biggs (2011) find they make more. In any case, both studies agree that public pensions are a larger share of state and local employees' compensation than private sector pensions are of private employees'.

${ }^{2}$ For example, see Gustman and Steinmeier (1993); Allen, Clark, and McDermed (1993); Gustman, Mitchell, and Steinmeier (1994); Haverstick, Munnell, Sanzenbacher, and Soto (2010).

${ }^{3}$ For example, see Ippolito (2002).

${ }^{4}$ Frazis and Loewenstein (2013).
} 
the Center for Retirement Research at Boston College, to measure the generosity of pension plans offered by state and local governments to their employees. The PPD includes data on the so-called "normal cost" of the pension, which is the present value of benefits accrued by active members in a calendar year, expressed as a share of payroll. As such, the normal cost reflects both the generosity of the plan and the actuarial assumptions made by the plan (e.g., discount rate, returns on investments, etc.). Once normalizing for differences in actuarial assumptions across locations, this study uses the normal cost as its proxy for pension generosity.

To obtain a measure of worker quality, the PPD data are then merged onto data from the Current Population Survey Outgoing Rotation Groups (CPS-ORG). The study uses the longitudinal feature of this dataset and an analysis adopted from Borjas (2002) to examine how a pension's normal cost affects the private sector wages of two groups of transitioning workers: 1) workers observed leaving the state and local sector for the private sector; and 2) workers observed entering the state and local sector from the private sector. If the group entering the state and local sector has lower private wages then the group leaving it, then workers who command higher private sector wages are sorting themselves out of the public sector, creating a “quality gap.” If relatively generous pensions reduce this quality gap in wages, then pensions may be seen as helping states and localities recruit and retain high-quality workers.

The fact that pensions are associated with higher retention of workers (ignoring worker quality for now) is well established and is true whether the pension is a defined benefit plan or a defined contribution plan (Gustman and Steinmeier (1993); Munnell, Haverstick, Sanzenbacher, and Soto (2010)). The latter point, that turnover is reduced by both defined contribution and defined benefit plans, calls into question one of the common explanations as to why pensions reduce turnover - that large capital losses associated with defined benefit formulas that backload accruals deter quitting (Ippolito (1987); Allen, Clark, and McDermed (1993)). But defined contribution plans do not have such formulas and thus do not have such losses. One explanation that emerged to fill the void is that offering deferred compensation, either through a defined benefit or a defined contribution plan, causes selection of workers who value such benefits. That is, these benefits attract workers who are "savers” and also “stayers” (Salop and Salop (1978); 
Allen, Clark, and McDermed (1993); Ippolito (2002)). ${ }^{5}$ Consistent with this explanation, Ippolito (2002) found that federal workers who participate in their 401(k)s were less likely to quit and also got higher job ratings, more promotions, and fewer disciplinary actions against them. This idea, that deferred compensation attracts "savers" who are also high-quality workers, serves as the main motivation for this study. Will state and local employers that reduce the deferred portion of their compensation packages see a subsequent decline in the quality of their workforce, failing to attract and retain high-quality "savers" who value these benefits? The results of this study suggest they may.

The empirical approach presented below focuses on workers transitioning between state or local government and the private sector. ${ }^{6}$ Once these workers are identified, two sets of regressions are run. The first set is a plan-level analysis of the relationship between a plan's normal cost and the gap in the private sector wages of workers leaving and entering the plan. This plan-level analysis suggests plans with higher normal costs have lower quality gaps and that the relationship is non-linear. Plans with the most generous pensions have the smallest quality gaps, but the relationship between normal cost and the quality gap is weak for plans with moderate normal costs. A consequence of this pattern is that results from the linear regressions, while consistent with expectations, are statistically insignificant.

Because the plan-level analysis throws away individual-level information and results in a relatively small sample, log-wage regressions are then run at the individual level, using the private sector wage as the dependent variable. These regressions include separate coefficients on normal cost (and other variables that may affect sorting) for state or local "enterers" and "leavers" through the introduction of interaction terms. These interaction terms identify the relationship between normal cost and the "quality gap" between the private sector wages of workers leaving the state and local sector and those entering it. When included linearly, our results suggest a 1-percentage-point increase in a pension's normal cost decreases this quality gap by a statistically significant 0.5 percentage points. This result is consistent with Ippolito's finding - more generous pensions help recruit high-wage private sector workers and

\footnotetext{
${ }^{5}$ Although their paper includes all benefits, not just pensions, Frazis and Loewenstein (2013) and Dale-Olsen (2006) find that benefits have a stronger effect on retention than wages and may do so by attracting workers who are less likely to quit.

${ }^{6}$ Federal workers are not included in the study.
} 
subsequently retain those workers. ${ }^{7}$ One desirable feature of the PPD data is that they contain information on the share of normal cost contributed by the employer and employee. In regressions that substitutes this information in for the total normal cost, it is found that the main result holds regardless of the share of the contributions coming from the employee and the employer.

The paper proceeds as follows: the next section presents the data, the third section describes the empirical specification and its motivation, the fourth section presents results, and the final section provides caveats and concludes that states and localities should be cautious as they reduce the generosity of their pensions, as it may affect the quality of the workers they are able to recruit and retain. Specifically, it suggests that increasing worker contributions to pensions may be an effective way to maintain the quality of the workforce while improving plan finances.

\section{The Data}

To estimate the relationship between pension generosity and the quality gap of workers entering and leaving the state or local sector requires merging several datasets. This merging is necessary because the CPS-ORG data used to follow workers between the public and private sectors contain information about pension coverage and no information about generosity. Thus, data on state and local pension generosity must be obtained from another source, in this case the Public Plans Database, and then merged with the CPS-ORG data. Both these datasets are described below as is the process for merging data between them.

Public Plans Database. The PPD is a comprehensive database of financial, governance, and plan design information for approximately 150 state and local defined benefit plans, spanning from 2001 to 2012. The data are maintained by the Center for Retirement Research at Boston College, which collects them through reviewing Comprehensive Annual Financial Reports (CAFRs) and Actuarial Valuations (AVs) of states' and localities’ pensions. The data cover over 85 percent of state and local employees in the United States.

\footnotetext{
${ }^{7}$ When normal cost is included non-linearly, the result is consistent with the quadratic plan-level analysis although the quadratic terms are insignificant.
} 
The data collected include a broad array of plan features, ranging from the pension board's assumptions on inflation and investment returns to actuarial data on wage growth to the pension's asset allocation. For the purposes of this study, the most important pieces of information collected by the PPD are the employers' and the employees' contribution to the normal cost of the pension. The normal cost is the present discounted value of the benefit an employee accrues during the fiscal year and is reported in the PPD as a percent of the state's total payroll. Given this definition, the normal cost is a function of two things: 1) the plan's benefit design and generosity; and 2) the assumptions used to calculate the total cost, particularly the discount rate.

On the first point, recent pension reforms provide a good example of the relationship between benefit generosity and the normal cost. For example, California reformed its Public Employees Retirement Fund (PERF) by increasing the age and tenure requirements for eligibility, reducing the benefit factor translating final wages to benefits, and increased the length of time used in calculating an average final salary (thus reducing the average). All these changes cause reductions in employee benefits. In the long run, these changes will reduce the normal cost of the pension from 19 to 14 percent of payroll. On the second point, the higher the discount rate, the less must be put aside today to pay benefits tomorrow. Thus, each plan's assumed rate of return is taken into account to construct a standardized normal cost variable reflecting primarily variance in benefits. ${ }^{8}$ To accomplish this, a rule of thumb approach identified after discussions with several actuaries is applied: the "standardized normal cost" of the pension in this study is the reported normal cost reduced (increased) by 25 percent for every 100 basis points the rate of return is below (above) the average.

Table 1 provides data over time on the number of plans in the PPD with non-missing normal cost data, the average normal cost, and the average standardized normal cost, as well as data on the average assumed rate of return and its standard deviation over time. Not surprisingly, following the financial crisis the average assumed rate of investment return dropped from 7.9 percent to 7.7 percent. Somewhat surprisingly, the average normal cost has not dropped substantially since the financial crisis, despite the fact that many states have implemented

\footnotetext{
${ }^{8}$ In practice, the normal cost within a pension plan may vary across individuals. This will be especially true going forward, when new employees will often be covered by less generous pension plans than their more tenured colleagues. A maintained assumption of this paper is that the average normal cost of a pension reflects the relative pension generosity of the plan, i.e., that plans with higher normal costs are on average more generous than other plans even given this internal variance.
} 
pension reforms. ${ }^{9}$ The reason is that most pension reforms apply only to new workers, a fact often due to state constitutional protections of pension benefits. ${ }^{10}$ (Public plan sponsors have gotten immediate relief by shifting the contributions for normal cost from the sponsor to the participant - see Table 2.)

However, this lack of movement masks large changes that will evolve as more workers are hired under reformed pensions. For example, California has increased its age/tenure requirements for benefit receipt, reduced its benefit factor, and increased the average salary period for its Public Employees Retirement Fund. All of these changes reduce the normal cost of the pension. Because the changes apply only to new workers, the average normal cost of this plan has remained nearly constant around 19 percent; however, estimates indicate a drop to 17 percent by 2028 and 14 percent by 2046 - an ultimate reduction of over 25 percent. Given that it is not possible to explore the impact of declining pension generosity over time, this study takes advantage of the existing variance in the generosity of pension plans across states and localities to analyze the potential effects of these future changes.

Although the average total normal cost has not dropped, Table 2 shows the average employer contribution to the standardized normal cost has dropped considerably. This decrease has been made up by increasing the employee contribution - a change that often applies to all workers, not just new employees. Between 2008 and 2012, employers’ contributions to normal cost dropped from 7.3 percent to 6.3 percent of payroll while the employee's contribution increased from 5.5 percent to 6.3 percent of payroll.

Once the standardized normal cost data displayed in Tables 1 and 2 are obtained, the groups of workers covered by each plan in the PPD are identified so that the PPD data can be merged with the CPS-ORG data. Some plans apply to all state workers (e.g., Alabama Employee Retirement System, Florida Retirement System, etc.), some apply to all local workers within a state (e.g., Colorado Municipal, Pennsylvania Municipal Employees Retirement System, etc.), others apply statewide to certain groups of workers, like firefighters, police, or teachers (e.g., Oklahoma Teachers Retirement Plan), while some apply only to workers within a specific city (e.g., Phoenix Employees Retirement System). Thus, for each plan in the PPD, the fiscal

\footnotetext{
${ }^{9}$ States implementing reforms include California, Connecticut, Florida, Georgia, Texas, and Wisconsin. It is also worth noting that the standardized normal cost does seem to decrease. The primary reason for this increase is the skewness of the distribution of assumed investment returns; in the final years of the PPD, the assumed investment return skews negative, meaning more plans have assumed rates of return below the average.

10 There is an excellent discussion of this issue in Brown and Wilcox (2009).
} 
year, state covered, city covered, worker occupation covered, and worker sector covered (state or local) is collected and used in the merge to the CPS-ORG data. ${ }^{11}$

\section{Current Population Survey Outgoing Rotation Group. The Current Population Survey} (CPS) is a joint effort between the U.S. Bureau of Labor Statistics and the U.S. Census Bureau and is the primary source of labor force statistics in the United States. The CPS is a probability sample of addresses, with all eligible residents of a sampled address surveyed. For purposes of this study, it provides demographic information on survey respondents including age, race, education, and state of residence and information on employment including class and sector of employment (private, state and local, federal, etc.), occupation, hours worked, and weekly earnings for some months. Because of the timing of interviews conducted by the CPS, discussed in detail below, some individuals can be followed from one year to the next and transitions in sector of employment identified.

When an address is selected for inclusion in the CPS, any eligible occupants will be interviewed eight times (unless they leave the address). These interviews are conducted nonconsecutively; interviews occur during the first four consecutive months, then eight months elapse, and interviews are restarted for an additional four consecutive months. An address's fourth and sixteenth months in the survey are called "Outgoing" months because its residents will either not be interviewed again for eight months (if in the fourth month) or will exit the sample entirely (if in the sixteenth month). Interviewees in the "Outgoing Rotation Group" are asked a more detailed set of questions than in other months - including their average weekly earnings. Because of the eight months off, individuals who remain at the same address have their outgoing interviews one year apart. If merged carefully, this longitudinal feature of the data can be used to determine if individuals who were working in the state and local sector in a given year transitioned to the private sector in the following year and vice versa.

Careful merging of the CPS-ORG data involves two steps: 1) use of CPS-provided identifiers to conduct an "initial" merge between the fourth and eighth months' interviews; ${ }^{12}$ and 2) "adjustment" of the initial merge by removing observations that the CPS identifiers indicate

\footnotetext{
${ }^{11}$ An implicit assumption is that a CPS respondent's address is representative of where they work. If it is unclear which state or local pension plan a CPS-ORG member would be covered by, he is assigned the most broad-based plan that could cover them, typically a statewide plan.

${ }^{12}$ This study uses the National Bureau of Economic Research's compilation of the CPS-ORG. Following Roth (2007) the variables used for this initial merge are: "hhid," "hhnum," "lineno," "intmonth,” and "state.”
} 
are the same individual but clearly are not because of a change in gender, race, or age. ${ }^{13}$ It is worth noting that even if the CPS identifiers were recorded perfectly, not all individuals could be followed from the fourth to eighth months of the survey due to non-response, mortality, and migration away from the sampled address.

Table 3 shows how the sample is whittled down from the full set of observations in their fourth month of the CPS, to the set of individuals who are initially merged to an eighth month observation, on down to the final adjusted merge that will be used in the study. For Table 3 and the analysis that follows, only full-time wage and salary workers ages 18-64 are included. Table 3 shows that about 75 percent of observations in their fourth month of CPS eligibility can be merged onto an observation in the sixteenth month, once invalid merges are removed. In general, the sample of individuals who are successfully merged across years is similar to the full sample, with the most notable differences being slightly higher rates of college completion (32.6 percent vs. 33.9 percent), slightly higher age (40.7 vs. 42.3), and slightly higher weekly earnings among those who were merged successfully (\$673 vs. \$711).

The merged CPS-ORG data are then merged onto the PPD data by matching the individual's state of residence, city of residence, occupation, and the year the individual is in the data. For local workers, the following priorities were used in the merge: 1) local workers in cities with their own municipal plan (e.g., Chicago Teachers, Denver Employees, etc.) were assigned the normal cost for that plan; 2) local workers in states with statewide municipal plans (e.g., Colorado Municipal, Maine Local, etc.) were assigned the normal cost for that plan; and 3) remaining local workers were assigned the relevant statewide plan for their occupation. State workers were assigned the relevant statewide plan for their occupation (e.g., Delaware State Employees, Georgia Teachers, etc.). This process results in 83 percent of state and local workers being assigned a pension plan and normal cost. The final dataset contains information on each individual's sector of employment over a two-year stretch, as well as the standardized normal cost of their pension plan during the time period they were a state or local worker.

\footnotetext{
13 This second step involves removing observations where 1) gender changes from the fourth to the sixteenth month; 2) race changes from the fourth to the sixteenth month; and 3) the individual appears to age by more than three years or becomes younger by more than one year between the fourth and the sixteenth months. The method here follows Madrian and Lefgren (1999), who hypothesize the recording errors arise in the identification variables because the primary purpose of the CPS is to work in the cross-section not as a panel and thus the longitudinal aspect of the data is not carefully checked. In any case, Madrian and Lefgren (1999) provide an excellent description of the procedure applied here as compared to other merging methodologies.
} 
Before proceeding with the empirical analysis, one final adjustment is made to the normal cost to account for the fact that data from the PPD reflect the normal cost as a share of payroll for pension covered workers only, not as a share of total payroll. Ideally, the sample in this study would be restricted to only pension-covered workers, but coverage data exist only for individuals in the March CPS - using these coverage data would force a reduction of the sample by 92 percent (11/12). Instead, state and local government pension coverage rates are estimated from the March Supplement to the CPS at the state-year level and multiplied by the normal cost assigned to each individual to obtain a normal cost as a share of total payroll, not just pension covered payroll as is found in the PPD. ${ }^{14}$

\section{Empirical Approach}

The study focuses on the private sector wages of 17,039 workers who were successfully merged onto normal cost data from the PPD and who 1) were just entering the state or local sector from the private sector; or 2) were just leaving the state or local sector to enter the private sector. Figure 1A shows the private sector wages of the two groups of interest for the period 1980 - 2012. Although the magnitude changes from year-to-year, workers leaving the state and local sector consistently command higher private sector wages than the workers coming into the sector did, 7 percent higher, on average. In other words, the state/local sector seems to have a problem retaining workers that command high private sector wages - there seems to be a “quality gap."15 During the period in which PPD data are available, 2001-2012, the quality gap is slightly smaller, averaging about 4 percent per year.

Table 4 summarizes the characteristics of the two groups of transitioning workers for the period 2001-2012 and shows that the samples of public sector enterers and leavers are similarly sized $^{16}$ and are fairly similar along the dimensions of gender, race, education, and age. Despite this similarity, Table 4 also shows that, between 2001 and 2012, workers entering the state or local sector made wages that were lower (\$688 versus \$709) than workers leaving it - a gap that

\footnotetext{
${ }^{14}$ For example, an individual who has been assigned a pension normal cost of 15 percent of covered payroll in a state and year where public sector employees have 80 percent coverage would have an adjusted normal cost of 12 percent of total payroll. A similar adjustment was made in Munnell, Aubry, Hurwitz, and Quinby (2011).

${ }^{15}$ Although one may expect a positive "quality gap" since one reason people may leave the state or local sector for the private sector is higher wages, it is worth noting that a similar gap does not exist for private sector workers entering and leaving the state or local sectors. As is shown in Figurer 1B, they have similar wages whether they are coming or going.

${ }^{16}$ In practice, this results from the fact that the private sector is considerably larger than the state and local sector, but has lower transition rates to the state and local sector than does the state and local sector to the private sector.
} 
indicates state and local employers are losing workers that command higher private sector wages than the workers they recruit. The question here is how the size of this gap varies based on a state or local employer's pension generosity. Is the quality gap smaller when the normal cost of pensions is higher?

To answer this question, two analyses of the quality gap are undertaken: one at the plan level and one at the individual level. The primary assumption of both approaches is the same: that the private sector wage of workers entering and leaving the state or local sectors can be used as a proxy for the worker's quality. The intuition is that workers who command high private sector wages are likely to have skills that also make them good public sector workers.

Plan-level Analysis. To conduct the plan-level analysis, the data are collapsed down to the plan-year level, so that each observation contains a plan's normal cost in that year as well as the demographic characteristics of the workers who entered and left the plan in that year (e.g., share male, share white, average age, etc.). Each observation also contains the average private sector wages of workers entering and leaving the plan, so that the quality gap can be calculated as:

$$
q_{j, t}=\frac{\breve{w}_{j, t+1}^{\text {leave }}-\overleftarrow{w}_{j, t-1}^{\text {enter }}}{\breve{w}_{j, t-1}^{\text {enter }}}
$$

where $\widetilde{w}_{j}$ is the average wage of the indicated group of workers. Each observation also contains some state-level ${ }^{17}$ information that could alter the quality gap, such as the state's unemployment rate, the average wage difference between the private and state and local sectors, ${ }^{18}$ and the relative wage compression in the state relative to the local sectors. ${ }^{19}$ Plan-years without any workers entering or leaving the plan are excluded by definition, which reduces the sample from 1,440 plan-years to 1,025. An additional 57 plan-years are removed because they are missing normal cost data, resulting in a final sample of 968 plan years.

\footnotetext{
${ }^{17}$ These differences are calculated at the state level as opposed to the local level because even in the relatively large sample obtained by using the CPS-ORG data, such analyses are infeasible.

18 This follows Borjas (2002). Differences in the mean and variance are calculated for each state, year, and gender separately and the average wage gap controls for educational level, race, marital status, and age.

${ }^{19}$ One of the primary hypotheses of Borjas (2002) is that states and localities with relatively compressed wage distributions will have trouble attracting high earning private sector workers, resulting in a larger gap.
} 
To conduct the analysis, the following linear regression is estimated:

$$
q_{j, t}=\alpha_{0}+\gamma N C_{j, t}+\left(D_{j, t}^{\text {leave }}-D_{j, t}^{\text {enter }}\right) \beta+S_{i, t} \theta+\varepsilon_{j, t}
$$

where $N C_{j, t}$ is the normal cost for pension $j$ in time $t$, and $D_{j, t}^{\text {leave }}-D_{j, t}^{e n t e r}$ represents "demographic gaps" that exist in the characteristics of workers who enter and leave. For example, if 50 percent of workers leaving an employer are college educated, but only 40 percent of workers entering are college educated, one would expect the education gap to increase the quality gap. By controlling for demographic gaps, it is possible to isolate the effect of pensions on the relative quality of leavers and enterers either conditional on demographics (by including these gaps) or unconditionally (by excluding them). As mentioned above, to the extent generous pensions help attract high-quality workers, they may do so either through workers from certain groups (e.g., college graduates) or through higher-quality workers within those groups. Thus, some specifications of the regression exclude these controls intentionally. ${ }^{20}$

The coefficient of interest in the regression is $\gamma$, which indicates the effect of normal cost on the quality gap. A negative (positive) coefficient indicates that pension plans with relatively high normal costs have lower (higher) quality gaps. The hypothesis is that $\gamma$ will be negative, because relatively generous pensions will help attract high-quality, high-wage earners and keep those workers. Because forcing the employee to bear some of the cost of the pension benefit may 1) be more salient to the employee; and 2) further discourage workers who don't value deferred compensation, some specifications include the following substitute in equation (1) for the normal cost variable:

$$
N C_{j, t}=N C_{j, t}^{E m p}+N C_{j, t}^{E E}
$$

where $N C_{i, t}^{E m p}$ represents the employer's contribution to the normal cost of the pension and $N C_{i, t}^{E E}$ represents the employees' contribution. This analysis is relevant since, as Table 2 shows, many states and localities have begun the process of shifting their pension costs onto employees. Finally, some specifications include a quadratic term in the normal cost, in case the relationship

${ }^{20}$ This approach is taken almost exclusively in Frazis and Loewenstein (2013). 
between normal cost and the quality gap is weak for plans with smaller pension plans. The planlevel approach has the advantage of being an intuitive way to analyze this problem, because the quality gap is measured directly as a function of the normal cost and other factors. However, it discards valuable individual-level variance in the wage and results in a small sample due to the number of plans that cannot be used. The individual-level analysis, adopted from Borjas (2002) avoids these issues.

Individual-level Analysis. Because the same individual cannot be observed both entering and leaving the state or local sector, the individual-level analysis treats each transitioning worker's private sector wage as the dependent variable and uses interaction terms to identify the relationship between the normal cost and the quality gap. To accomplish this, the following logwage regression is estimated:

$$
\log w_{i, t}=X_{i, t} \beta^{\prime}+\gamma_{0} L_{i, t}+\gamma_{1} N C_{i, t^{\prime}}+\gamma_{2} L_{i, t} * N C_{i, t^{\prime}}+S_{i, t} \theta^{\prime}+L_{i, t} * S_{i, t} \vartheta+\varepsilon_{i, t}
$$

where $w_{i, t}$ is the private sector wage of person $i$ in time $t$. The variable $L_{i, t}$ is an indicator variable that takes on a value of 1 if the person is exiting the state or local sector for the private sector and 0 if they are entering the state or local sector. The other independent variables include $X_{i, t}$, a vector of demographic characteristics; $N C_{i, t}$, the normal cost in an individual's state or local pension plan during the period in which they were employed in that sector (this would be $\mathrm{t}+1$ for state and local "enterers" and $\mathrm{t}-1$ for state and local "leavers"); and $S_{i, t}$,which is a vector of state characteristics, some of which may also influence sorting of high-quality workers into and out of the state and local sectors.

The coefficients of interest in this regression are $\gamma_{1}$ and $\gamma_{2}$, which indicate how the normal cost is related to the private sector wages of workers transitioning between the private and state or local sectors. A positive (negative) value for $\gamma_{1}$ indicates that states or localities with higher normal cost pensions are attracting workers who had higher (lower) private sector wages compared to other states and localities. If $\gamma_{2}$ is negative (positive), this indicates the state or locality loses lower (higher) private sector earners than it is gaining, at least relative to other areas with relatively less generous pensions. A negative coefficient on $\gamma_{2}$ would indicate that 
states and localities with relatively generous pensions have smaller quality gaps than similar states with less generous pensions.

The hypothesis of this study, based on existing literature, is that $\gamma_{1}$ will be positive and $\gamma_{2}$ will be negative, indicating high-quality workers who command higher private sector wages will sort into state or local government employers with generous pensions and will be retained by those employers. The intuition for this hypothesis is that although states and localities typically offer lower wages to comparable employees than private sector employers, they also typically offer more generous pensions. ${ }^{21}$ To the extent this compensation package attracts workers who tend to value deferred compensation over wages, and to the extent these workers tend to be highquality "savers," it suggests a positive $\gamma_{1}$. To the extent these workers also tend to be "stayers," it stands to reason that those who command the highest private sector wages may also be more likely to stay than other workers, leading to a negative value for $\gamma_{2}$. As above, some specifications substitute equation (3) as the measure of normal cost.

Aside from the normal cost of the pension, the independent variables include demographic controls for gender, race, marital status, level of education, and age. For the reasons discussed above, some specifications of the regression exclude these controls intentionally. Also as above, some specifications control for state-level differences between the wage distribution of the state and local and private sectors (both between average wages and in the variance of wages), the size of the state and local sector relative to the private sector, and the unemployment rate in the private sector.

\section{Results}

Results from the regressions appear in Tables 5A-5D. Tables 5A-5B show results from the plan-level analysis and 5C-5D the individual-level analysis.

Plan-level analysis. The results of the plan-level analysis using total normal cost are consistent with expectations - the coefficient on the total normal cost is negative in each linear specification of equation (1), shown in Table 5A. For example, when controlling for both demographics and state characteristics, the coefficient on the total normal cost suggests that a 1-

\footnotetext{
${ }^{21}$ Munnell, Aubry, Hurwitz, and Quinby (2011).
} 
percent increase in the normal cost of a pension results in a 0.17 percent reduction in the quality gap. However, in the linear specifications, the coefficients are statistically insignificant.

The reason for this statistical insignificance is likely threefold. First, condensing the sample to the plan-level eliminates individual-level variation in the data. Second, it throws away information from approximately 2,104 individuals (12 percent of the sample) in plans that didn’t have any workers either entering or leaving it in a given year - equation (1) illustrates both sets of workers are necessary to calculate the quality gap. Finally, as the quadratic specification shows, at the plan-level the relationship between normal cost and the quality gap is non-linear. Specifically, the negative and significant coefficient on the quadratic term suggests that the relationship between normal cost and the quality gap is stronger for plans with high normal costs and relatively generous pensions.

As an example of the magnitude of the marginal effects under this quadratic specification, at a normal cost level of 15 , which is above the average normal cost, the effect of a 1-percentage point increase in the normal cost would be to decrease the quality gap by 1.4 percentage points (statistically significant to the 10-percent level). Considering that the quality gap during this time period was 4 percent, the difference is non-trivial. However, at lower normal costs the estimated relationship between normal cost and the quality gap is insignificant and at very low levels of normal cost, is actually positive, although this positive relationship is generally not statistically significant until the normal cost is below levels observed in the data.

Substituting equation (2) into equation (1), Table 5B shows that the direction of the coefficients of interest are again negative and are again not statistically significant. In other words, the plan-level analysis suggests that relatively generous pension plans have smaller quality gaps, but these results are not conclusive. It is worth noting that the coefficient on the employee's contribution to normal cost is generally higher than on the employer's, suggesting that more generous pensions may reduce the quality gap regardless of who pays for it. However, caution must be exercised. The coefficient on the employee's contribution to normal cost is not statistically significant nor is it significantly larger than the coefficient on the employer normal cost. To better exploit the richness of the CPS-ORG data, the study turns now to the individuallevel analysis. 
Individual-level analysis. Table 5C contains various specifications of equation (4), while Table 5D substitutes in equation (3) for the normal cost, taking advantage of the fact that the PPD collects data on both employer and employee contributions to the total normal cost of the pension.

The results in Table 5C suggest that, absent controls, states with generous pension plans, as captured by high normal costs, hire workers with significantly higher private sector wages. The effect of the interaction term between the normal cost and the variable indicating an individual leaving the state or local sector, which represents $\gamma_{2}$ in equation (4), is statistically insignificant. However, once demographic controls are introduced (as in specifications 2, 4, and 5), both coefficients are significant and in the expected direction. This result suggests that more generous pensions reduce the quality gap, especially within demographic groups. The magnitude of the effect, while not huge, is not trivial either. For example, from 2001-2012, the period being analyzed, the average gap in private sector wages between workers leaving the state or local sector and entering it was 4 percent. The estimates from the specification controlling for both demographics and state characteristics (specification 4) suggest that a 1-percentage-point increase in the normal cost is associated with a 0.5 percentage point reduction in the quality gap, or roughly 12 percent. ${ }^{22}$

Coefficients on the demographic controls are generally intuitive - males, non-blacks, married individuals, older individuals, and individuals with more education all have higher private sector wages. ${ }^{23}$ In our preferred specification, which includes both demographic controls

\footnotetext{
${ }^{22}$ The results from the quadratic specification are statistically insignificant. It is worth noting that two sensitivities were run on this specification to verify the consistency of the results given necessary assumptions made in the course of this analysis. First, because many local workers cannot be assigned a local plan and are instead assigned a statewide plan (see CPS ORG data section above), a sensitivity was run only on state workers, i.e., workers who do not require such an assignment. The results from this sensitivity were consistent - a 1 percentage point increase in the normal cost was associated with a 0.7 percentage point reduction in the quality gap. The result was not statistically significant $(\mathrm{p}=0.12)$. Second, because only the March Supplement to the CPS contains data on pension participation, the analysis includes individuals regardless of actual pension coverage and adjusts the normal cost by the share of individuals in the state or locality covered by a pension (see CPS ORG data section above). A sensitivity was run restricting the analysis to only individuals whose outgoing interview was in March and who claimed they were enrolled in their state or local pension. For this sensitivity, no adjustment for pension coverage was made. The results were again consistent, albeit based on a sample of just 300 workers - a one percentage point increase in the normal cost was associated with a -2.7 percent reduction in the quality gap and the result is significant $(\mathrm{p}=0.05)$.

${ }^{23}$ These demographic variables are not interacted with the variable indicating exit from the state or local sector. They are meant to control for compositional differences in the share of people entering or leaving state or local government.
} 
and state-level controls (but not state-level dummies), most of the state-level controls are statistically insignificant.

The results in Table 5D replace the measure of total normal cost with the amounts of that cost paid by employers and employees. In each specification, save for the one lacking any controls, the signs on the coefficients of interest are negative and in the expected direction. For specifications with controls, the coefficients on the employer's contribution to normal cost range from -0.4 percent to -0.6 percent and on the employee's contribution -0.3 percent to -0.5 percent. All of these coefficients indicate a reduction in the quality gap, although they are often not statistically significant. However, in the preferred specification (specification 4), which controls for both demographic and state-level variables, both the employer and employee contribution are found to significantly reduce the quality gap. The employer's contribution to normal cost is associated with a 0.6 percentage point reduction in the quality gap per 1-percentage-point increase in the contribution, while the employee's contribution a similar 0.5 percentage-point reduction. This result suggests that regardless of who is paying the normal cost, states with more generous pension benefits attract workers who were earning more in the private sector and lose workers earning relatively less. Given the selection angle the recent literature has taken, this makes sense. Conditional on the wage, a worker who does not value pensions seems unlikely to accept or stay in a job where they pay a large share of their salary towards pensions, whereas a worker who does value them would.

\section{Conclusion}

States and localities have reduced the generosity of their pensions for new hires. What will the impact of this be on state and local governments' ability to recruit and retain high quality workers? This paper suggests it may be detrimental.

The results are fairly consistent across specifications. More generous pensions are associated with higher private sector wages for workers entering the state or local sector and comparatively lower wages for those leaving. Relatively generous pensions do seem to reduce the quality gap. This is true whether the analysis is conducted at the plan- or individual-level, although the results from the plan-level analysis were generally insignificant, except for the quadratic specification. Moreover, because the coefficients on employers' and employees’ contributions to pensions are similar, it suggests that reducing the employers' contribution (and 
presumably redistributing some of that money toward the plan's fund) and increasing the employee's contribution is one way to mitigate the effects of the necessary fiscal tightening of pension plans.

Of course, an important caveat must be kept in mind. The lack of information on the generosity of other benefits in the state and local sector makes the result difficult to interpret causally. In particular, states and localities generally offer generous health plans relative to the private sector and the generosity of these plans may be correlated with pension benefits. If highquality workers also value health insurance, then the result expressed here may be more muted than it appears. 


\section{References}

Allen, S.G., R.L. Clark, A.A. McDermed. 1993. “Pensions, Bonding, and Lifetime Jobs.” The Journal of Human Resources 28(3): 463-481.

Borjas, G.J. 2012. "The Wage Structure and the Sorting of Workers into the Public Sector.” Working Paper 9313. Cambridge, MA: National Bureau of Economic Research.

Brown, J.R. and D.W. Wilcox. 2009. “Discounting State and Local Pension Liabilities.” American Economic Review 99(2): 538-542.

Dale-Olsen, H. 2006. "Wages, Fringe Benefits, and Worker Turnover.” Labour Economics 13(1): 87-105.

Fraziz, H. and M.A. Loewenstein. 2013. “How Responsive are Quits to Benefits?” Journal of Human Capital 48(4): 969-997.

Gustman, A.L., O.S. Mitchell, and T.L. Steinmeier. 1994. "The Role of Pensions in the Labor Market: A Survey of the Literature.” Industrial and Labor Relations Review 47(3): 417438.

Gustman, A.L. and T.L. Steinmeier. 1993. "Pension Portability and Labor Mobility: Evidence from the Survey of Income and Program Participation.” Journal of Public Economics 50(3): 299-323.

Haverstick, K., A.H. Munnell, G. Sanzenbacher, and M. Soto. "Pension Type, Tenure, and Job Mobility.” Journal of Pension Economics and Finance 9(4): 609-625.

Ippolito, R.A. 1987. “Why Federal Workers Don’t Quit.” The Journal of Human Resources 22(2): 281-299.

Ippolito, R.A. 2002. “Stayers as 'Workers' and 'Savers': Toward Reconciling the Pension-Quit Literature.” The Journal of Human Resources 37(2): 275-308.

Madrian, B.C. and L.J. Lefgren. 1999. “A Note on Longitudinally Matching Current Population Survey (CPS) Respondents.” Technical Working Paper 247. Cambridge, MA: National Bureau of Economic Research.

Munnell, A.H., J.P. Aubry, J. Hurwitz, and L. Quinby. 2011. "Comparing Compensation: StateLocal Versus Private Sector Workers.” State and Local Pension Plans Issue in Brief 20. Chestnut Hill, MA: Center for Retirement Research at Boston College.

Public Plans Database. 2001-2012. Center for Retirement Research at Boston College and Center for State and Local Government Excellence. 
Richwine, J. and A. Biggs. 2011. “Are California Public Employees Overpaid?” Working Paper. Washington, DC: Heritage Foundation.

Roth, J. and D. Feenberg. 2007. “CPS Labor Extracts.” Cambridge, MA: National Bureau of Economic Research.

Salop, J. and S. Salop. 1976. "Self-Selection and Turnover in the Labor Market.” Quarterly Journal of Economics 90(4): 620-627.

U.S. Census Bureau. Current Population Survey Outgoing Rotation Groups, 2000-2013. Data accessed from Cambridge, MA: National Bureau of Economic Research. 
Table 1. Summary of Total Normal Cost and the Assumed Rate of Return across Public Pension Plans, 2001-2012

\begin{tabular}{|c|c|c|c|c|c|}
\hline \multirow[b]{2}{*}{ Year } & \multicolumn{2}{|c|}{ Average Normal Cost } & & \multicolumn{2}{|c|}{ Assumed Investment Return } \\
\hline & Unstandarized & Standardized $^{1}$ & & Average & Standard Deviation \\
\hline 2001 & $11.1 \%$ & $11.1 \%$ & & $8.0 \%$ & 0.356 \\
\hline 2002 & $12.1 \%$ & $12.2 \%$ & & $8.0 \%$ & 0.374 \\
\hline 2003 & $12.4 \%$ & $12.4 \%$ & & $8.0 \%$ & 0.367 \\
\hline 2004 & $12.6 \%$ & $12.6 \%$ & & $8.0 \%$ & 0.338 \\
\hline 2005 & $12.7 \%$ & $12.7 \%$ & & $7.9 \%$ & 0.340 \\
\hline 2006 & $12.8 \%$ & $12.8 \%$ & & $7.9 \%$ & 0.333 \\
\hline 2007 & $12.8 \%$ & $12.7 \%$ & & $7.9 \%$ & 0.333 \\
\hline 2008 & $12.9 \%$ & $12.8 \%$ & & $7.9 \%$ & 0.309 \\
\hline 2009 & $13.3 \%$ & $13.2 \%$ & & $7.9 \%$ & 0.296 \\
\hline 2010 & $13.3 \%$ & $13.1 \%$ & & $7.8 \%$ & 0.359 \\
\hline 2011 & $13.2 \%$ & $12.9 \%$ & & $7.7 \%$ & 0.364 \\
\hline 2012 & $13.1 \%$ & $12.5 \%$ & & $7.7 \%$ & 0.333 \\
\hline
\end{tabular}

${ }^{1}$ Calculated as: [Norm Cost $+\left(0.25 *\right.$ Normal Cost ${ }^{*}$ Demeaned Rate of Return $\left.)\right]$ where the demeaned rate of return is equal to the difference between the plan's assumed rate of return and the average rate of return within a given year. Note: All numbers shown are weighted by the total number of active members in the plan. Source: Public Plans Database, 2001-2012. 
Table 2. Summary of Contributions to Normal Cost across Public Pension Plans, 2001-2012

\begin{tabular}{|c|c|c|c|c|}
\hline \multirow[b]{2}{*}{ Year } & \multirow[b]{2}{*}{ Normal Cost } & \multicolumn{2}{|c|}{ Normal Cost Contribution From: } & \multirow[b]{2}{*}{ Share Paid by Employees } \\
\hline & & Employers & Employees & \\
\hline 2001 & $11.1 \%$ & $6.0 \%$ & $4.8 \%$ & $43.6 \%$ \\
\hline 2002 & $12.2 \%$ & $6.3 \%$ & $5.2 \%$ & $42.9 \%$ \\
\hline 2003 & $12.4 \%$ & $7.5 \%$ & $5.1 \%$ & $40.8 \%$ \\
\hline 2004 & $12.6 \%$ & $7.5 \%$ & $5.2 \%$ & $41.5 \%$ \\
\hline 2005 & $12.7 \%$ & $7.4 \%$ & $5.4 \%$ & $42.4 \%$ \\
\hline 2006 & $12.8 \%$ & $7.4 \%$ & $5.4 \%$ & $42.5 \%$ \\
\hline 2007 & $12.7 \%$ & $7.4 \%$ & $5.5 \%$ & $42.9 \%$ \\
\hline 2008 & $12.8 \%$ & $7.3 \%$ & $5.5 \%$ & $43.2 \%$ \\
\hline 2009 & $13.2 \%$ & $7.6 \%$ & $5.6 \%$ & $42.6 \%$ \\
\hline 2010 & $13.1 \%$ & $7.6 \%$ & $5.6 \%$ & $42.7 \%$ \\
\hline 2011 & $12.9 \%$ & $7.0 \%$ & $5.9 \%$ & $45.5 \%$ \\
\hline 2012 & $12.5 \%$ & $6.3 \%$ & $6.3 \%$ & $50.0 \%$ \\
\hline
\end{tabular}

Notes: All calculations use the standardized normal cost. All numbers shown are weighted by the total number of active members in the plan.

Source: Public Plans Database, 2001-2012. 
Table 3. Summary Statistics Following CPS Year-to-Year Merge, 2001-2012

\begin{tabular}{|c|c|c|c|c|c|c|}
\hline \multirow{4}{*}{ Total } & \multicolumn{2}{|c|}{ All Observations } & \multicolumn{2}{|c|}{ Initial Merge } & \multicolumn{2}{|c|}{ Adjusted Merge } \\
\hline & Number & Share & Number & Share & Number & Share \\
\hline & 901,846 & $100 \%$ & 703,334 & $100 \%$ & 680,236 & $100 \%$ \\
\hline & & & \multicolumn{2}{|c|}{$78 \%$ of all obs. } & \multicolumn{2}{|c|}{$75 \%$ of all obs. } \\
\hline \multicolumn{7}{|l|}{ Sector } \\
\hline Private & 739,954 & $82.0 \%$ & 568,226 & $80.8 \%$ & 548,450 & $80.6 \%$ \\
\hline Federal & 32,104 & $3.6 \%$ & 26,237 & $3.7 \%$ & 25,504 & $3.7 \%$ \\
\hline State and Local & 129,788 & $14.4 \%$ & 108,871 & $15.5 \%$ & 106,282 & $15.6 \%$ \\
\hline \multicolumn{7}{|l|}{ Race } \\
\hline Non-black & 812,316 & $90.1 \%$ & 637,210 & $90.6 \%$ & 617,373 & $90.8 \%$ \\
\hline Black & 89,530 & $9.9 \%$ & 66,124 & $9.4 \%$ & 62,863 & $9.2 \%$ \\
\hline \multicolumn{7}{|l|}{ Education } \\
\hline Less than High School & 76,391 & $8.5 \%$ & 53,537 & $7.6 \%$ & 50,853 & $7.5 \%$ \\
\hline High School Graduate & 274,693 & $30.5 \%$ & 211,227 & $30.0 \%$ & 204,071 & $30.0 \%$ \\
\hline Some College & 257,037 & $28.5 \%$ & 200,691 & $28.5 \%$ & 194,557 & $28.6 \%$ \\
\hline College Graduate & 293,725 & $32.6 \%$ & 237,879 & $33.8 \%$ & 230,755 & $33.9 \%$ \\
\hline Average Age & \multicolumn{2}{|c|}{40.7} & \multicolumn{2}{|c|}{42.2} & \multicolumn{2}{|c|}{42.3} \\
\hline Average Weekly Hours & \multicolumn{2}{|c|}{42.4} & \multicolumn{2}{|c|}{42.4} & \multicolumn{2}{|c|}{42.4} \\
\hline Median Weekly Earnings & \multicolumn{2}{|c|}{$\$ 673.07$} & \multicolumn{2}{|c|}{$\$ 700.00$} & \multicolumn{2}{|c|}{$\$ 711.00$} \\
\hline
\end{tabular}

Notes: Includes only individuals aged 18-64 working in a wage or salary position 35 or more hours per week and earning at least 90 dollars per week. 2013 CPS dataare used to identify 2012 observations that can be merged. Source: Current Population Survey Outgoing Rotation Groups, 2001-2013. 
Table 4. Comparison of Workers Entering and Leaving the State and Local Sector, 2001-2012

\begin{tabular}{|c|c|c|c|c|}
\hline & \multicolumn{2}{|c|}{ Entering State/Local Sector } & \multicolumn{2}{|c|}{ Leaving State/Local Sector } \\
\hline & Observations & Share of Obs & Observations & Share of Obs \\
\hline Total Observations & 8,411 & $100 \%$ & 8,628 & $100 \%$ \\
\hline Total Normal Cost & \multicolumn{2}{|c|}{$12.1 \%$} & \multicolumn{2}{|c|}{$12.0 \%$} \\
\hline From Employer & \multirow{2}{*}{\multicolumn{2}{|c|}{$\begin{array}{l}6.9 \% \\
5.1 \%\end{array}$}} & \multicolumn{2}{|c|}{$6.9 \%$} \\
\hline From Employee & & & \multicolumn{2}{|c|}{$5.1 \%$} \\
\hline Male & 3,336 & $39.7 \%$ & 3,384 & $39.2 \%$ \\
\hline Black & 1,242 & $14.8 \%$ & 1,319 & $15.3 \%$ \\
\hline Married & 5,380 & $64.0 \%$ & 5,551 & $64.3 \%$ \\
\hline \multicolumn{5}{|l|}{ Education } \\
\hline Less than High School & 347 & $4.1 \%$ & 358 & $4.3 \%$ \\
\hline High School & 1,943 & $23.1 \%$ & 1,871 & $22.2 \%$ \\
\hline Some College & 2,210 & $26.3 \%$ & 2,140 & $25.4 \%$ \\
\hline 4-year College Graduate & 3,911 & $46.5 \%$ & 4,043 & $48.1 \%$ \\
\hline Average Age & \multicolumn{2}{|c|}{42.3} & \multicolumn{2}{|c|}{43.0} \\
\hline Weekly Private Sector Wage & \multicolumn{2}{|c|}{$\$ 687.89$} & \multicolumn{2}{|c|}{$\$ 708.91$} \\
\hline
\end{tabular}

Notes: Includes only individuals aged 18-64 working in a wage or salary position 35 or more hours per week and earning at least 90 dollars per week in both the year they were employed in the private sector and the year they were employed in the state/local sector. 2013 data are used for individuals who leave the state/local sector between 2012 and 2013. Even though PPD data are only available through 2012, because these individuals were employed in the state/local sector in 2012, the observations are usable.

Sources: Current Population Survey Outgoing Rotation Groups, 2001-2013; and Public Plans Database, 20012012. 
Table 5A. Plan-level Regressions using Total Normal Cost

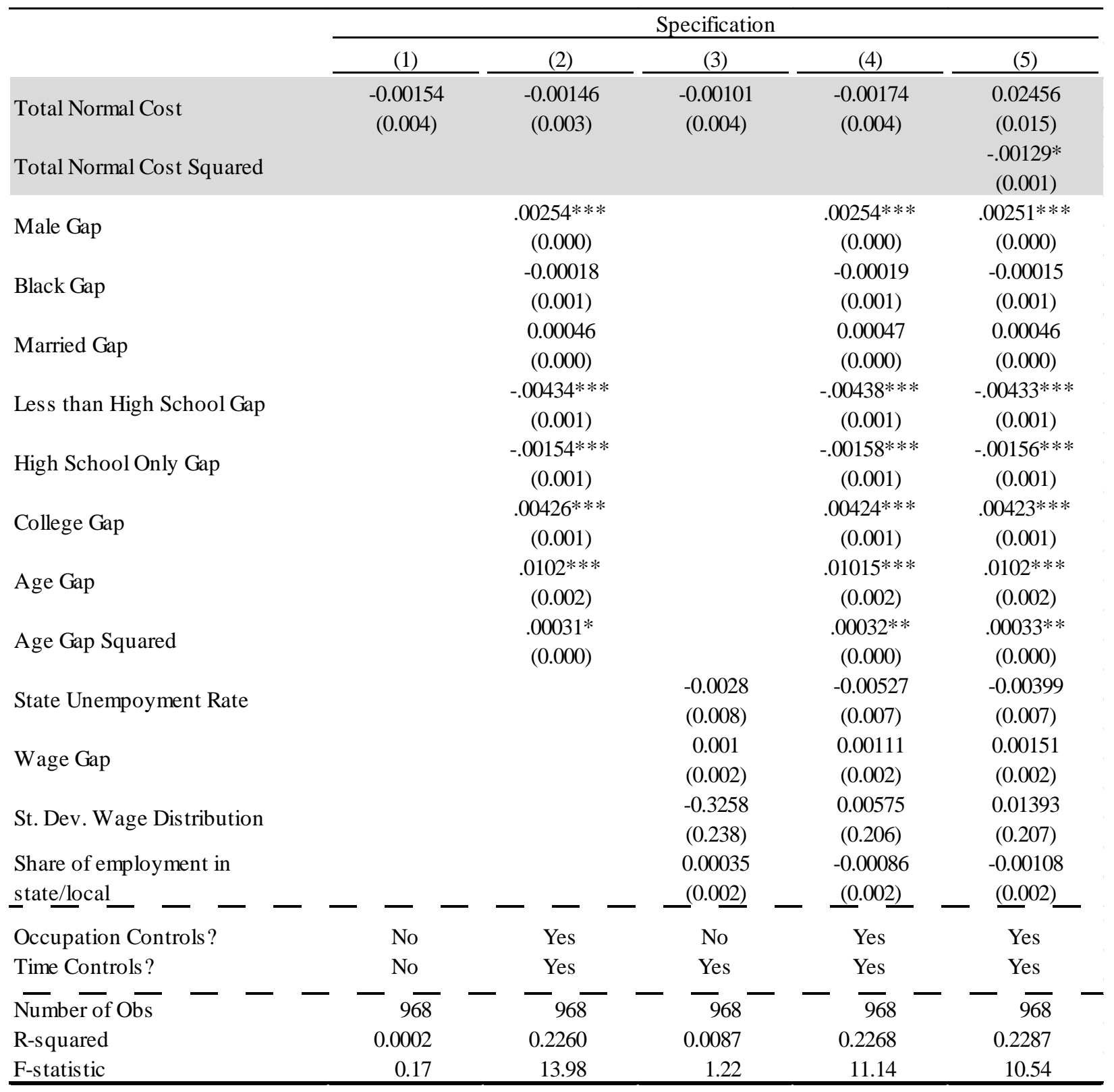

Notes: *** - significance at 1 percent; ${ }^{* *}$ - significance at 5 percent; * - significance at 1 percent. Regression weighted by number of individuals leaving and entering plan. Numbers in parenthesis are robust standard errors. Sources: Current Population Survey Outgoing Rotation Groups, 2001-2013; and Public Plans Database, 20012012. 
Table 5B. Plan-level Regressions using Employer and Employee Contributions to Normal Cost

\begin{tabular}{|c|c|c|c|c|c|}
\hline & & & Specificatio & & \\
\hline & $(1)$ & (2) & (3) & (4) & (5) \\
\hline Total Employer Normal Cost & $\begin{array}{l}0.0006 \\
(0.005)\end{array}$ & $\begin{array}{l}-0.00023 \\
(0.004)\end{array}$ & $\begin{array}{c}0.00073 \\
(0.005)\end{array}$ & $\begin{array}{l}-0.00085 \\
(0.005)\end{array}$ & $\begin{array}{l}0.0053 \\
(0.014)\end{array}$ \\
\hline $\begin{array}{l}\text { Total Employer Normal Cost } \\
\text { Squared }\end{array}$ & & & & & $\begin{array}{c}-0.00048 \\
(0.001)\end{array}$ \\
\hline Total Employee Normal Cost & $\begin{array}{c}-0.00416 \\
(0.005)\end{array}$ & $\begin{array}{l}-0.00296 \\
(0.004)\end{array}$ & $\begin{array}{c}-0.00482 \\
(0.005)\end{array}$ & $\begin{array}{c}-0.00254 \\
(0.004)\end{array}$ & $\begin{array}{c}-0.01318 \\
(0.013)\end{array}$ \\
\hline $\begin{array}{l}\text { Total Employee Normal Cost } \\
\text { Squared }\end{array}$ & & & & & $\begin{array}{c}0.00121 \\
(0.001)\end{array}$ \\
\hline Male Gap & & $\begin{array}{c}.00254^{* * *} \\
(0.000)\end{array}$ & & $\begin{array}{c}.00254^{* * *} \\
(0.000)\end{array}$ & $\begin{array}{c}.00252^{* * *} \\
(0.000)\end{array}$ \\
\hline Black Gap & & $\begin{array}{c}-0.00018 \\
(0.001)\end{array}$ & & $\begin{array}{c}-0.00019 \\
(0.001)\end{array}$ & $\begin{array}{c}-0.00015 \\
(0.001)\end{array}$ \\
\hline Married Gap & & $\begin{array}{l}0.00046 \\
(0.000)\end{array}$ & & $\begin{array}{l}0.00047 \\
(0.000)\end{array}$ & $\begin{array}{l}0.00048 \\
(0.000)\end{array}$ \\
\hline Less than High School Gap & & $\begin{array}{c}-.00435 * * * \\
(0.001)\end{array}$ & & $\begin{array}{c}-.00438 * * * \\
\quad(0.001)\end{array}$ & $\begin{array}{c}-.00442 * * * \\
(0.001)\end{array}$ \\
\hline High School Only Gap & & $\begin{array}{l}-.00154^{* * *} \\
\quad(0.001)\end{array}$ & & $\begin{array}{l}-.00157 * * * \\
\quad(0.001)\end{array}$ & $\begin{array}{c}-.00159 * * * \\
(0.001)\end{array}$ \\
\hline College Gap & & $\begin{array}{c}.00425 * * * \\
(0.001)\end{array}$ & & $\begin{array}{c}.00424 * * * \\
(0.001)\end{array}$ & $\begin{array}{c}.00421^{* * *} \\
(0.001)\end{array}$ \\
\hline Age Gap & & $\begin{array}{l}.01016 * * * \\
(0.002)\end{array}$ & & $\begin{array}{l}.01013^{* * *} \\
(0.002)\end{array}$ & $\begin{array}{c}.01008^{* * *} \\
(0.002)\end{array}$ \\
\hline Age Gap Squared & & $\begin{array}{r}.00031^{*} \\
(0.000)\end{array}$ & & $\begin{array}{c}.00032 * * \\
(0.000)\end{array}$ & $\begin{array}{c}.00031^{*} \\
(0.000)\end{array}$ \\
\hline State Unempoyment Rate & & & $\begin{array}{l}0.00555 \\
(0.006)\end{array}$ & $\begin{array}{c}-0.00525 \\
(0.007)\end{array}$ & $\begin{array}{c}-0.00588 \\
(0.007)\end{array}$ \\
\hline Wage Gap & & & $\begin{array}{l}0.00037 \\
(0.002)\end{array}$ & $\begin{array}{c}0.00092 \\
(0.002)\end{array}$ & $\begin{array}{l}0.00108 \\
(0.002)\end{array}$ \\
\hline St. Dev. Wage Distribution & & & $\begin{array}{l}-0.2965 \\
(0.237)\end{array}$ & $\begin{array}{l}0.0047 \\
(0.206)\end{array}$ & $\begin{array}{c}-0.00814 \\
(0.208)\end{array}$ \\
\hline $\begin{array}{l}\text { Share of employment in } \\
\text { state/local }-\ldots-\end{array}$ & - & - & $\begin{array}{l}0.00088 \\
\underline{(0.002)}\end{array}$ & $\begin{array}{r}-0.00079 \\
-(0.002) \\
\end{array}$ & $\begin{array}{r}-0.0004 \\
-(0.002) \\
\end{array}$ \\
\hline Occupation Dummies? & No & Yes & No & Yes & Yes \\
\hline Time Controls? & No & Yes & Yes & Yes & Yes \\
\hline$\overline{\text { Number of Obs }}-$ & $\overline{9} 68$ & $\overline{968}$ & $-\overline{968}$ & $-\quad-96 \overline{8}$ & -968 \\
\hline R-squared & 0.0008 & 0.2262 & 0.0038 & 0.2268 & 0.2276 \\
\hline F-statistic & 0.38 & 13.13 & 0.73 & 10.59 & 9.83 \\
\hline
\end{tabular}

Notes: *** - significance at 1 percent; ${ }^{* *}$ - significance at 5 percent; ${ }^{*}$ - significance at 1 percent. Regression weighted by number of individuals leaving and entering plan. Numbers in parenthesis are robust standard errors. Sources: Current Population Survey Outgoing Rotation Groups, 2001-2013; and Public Plans Database, 20012012. 
Table 5C. Individual-level Regression Results using Total Normal Cost

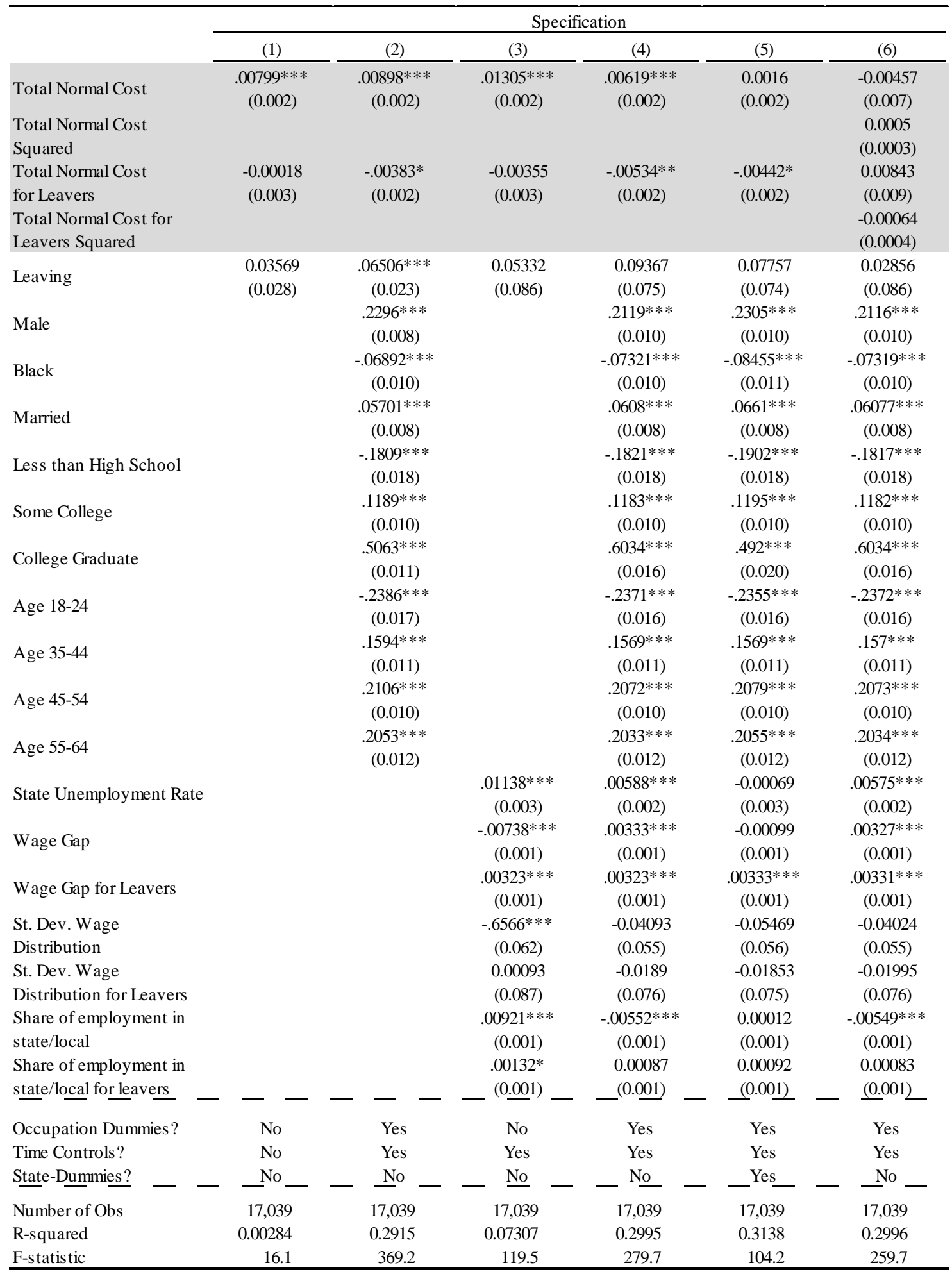

Notes: *** - significance at 1 percent; ${ }^{* *}$ - significance at 5 percent; * - significance at 1 percent. Numbers in parenthesis are robust standard errors.

Sources: Current Population Survey Outgoing Rotation Groups, 2001-2013; and Public Plans Database, 20012012. 
Table 5D. Individual-level Regression Results using Employer and Employee Contributions to Normal Cost

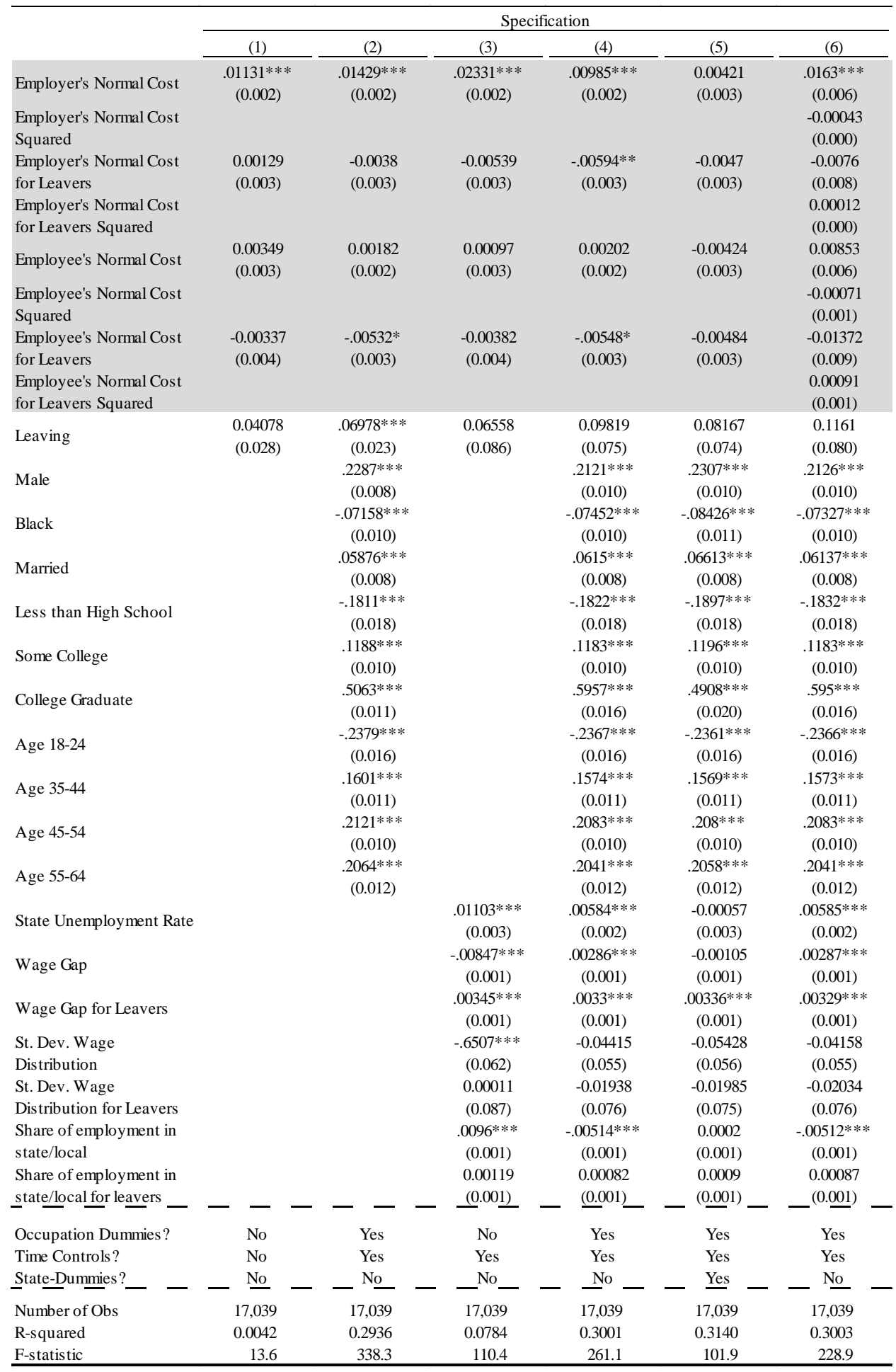

Notes: ${ }^{* * *}$ - significance at 1 percent; ${ }^{* *}$ - significance at 5 percent; * - significance at 1 percent. Numbers in parenthesis are robust standard errors.

Sources: Current Population Survey Outgoing Rotation Groups, 2001-2013; and Public Plans Database, 20012012. 
Figure 1A. Average Real Private sector Weekly Earnings of Full-Time Workers Entering and Leaving the State/Local Sector, 1980-2012

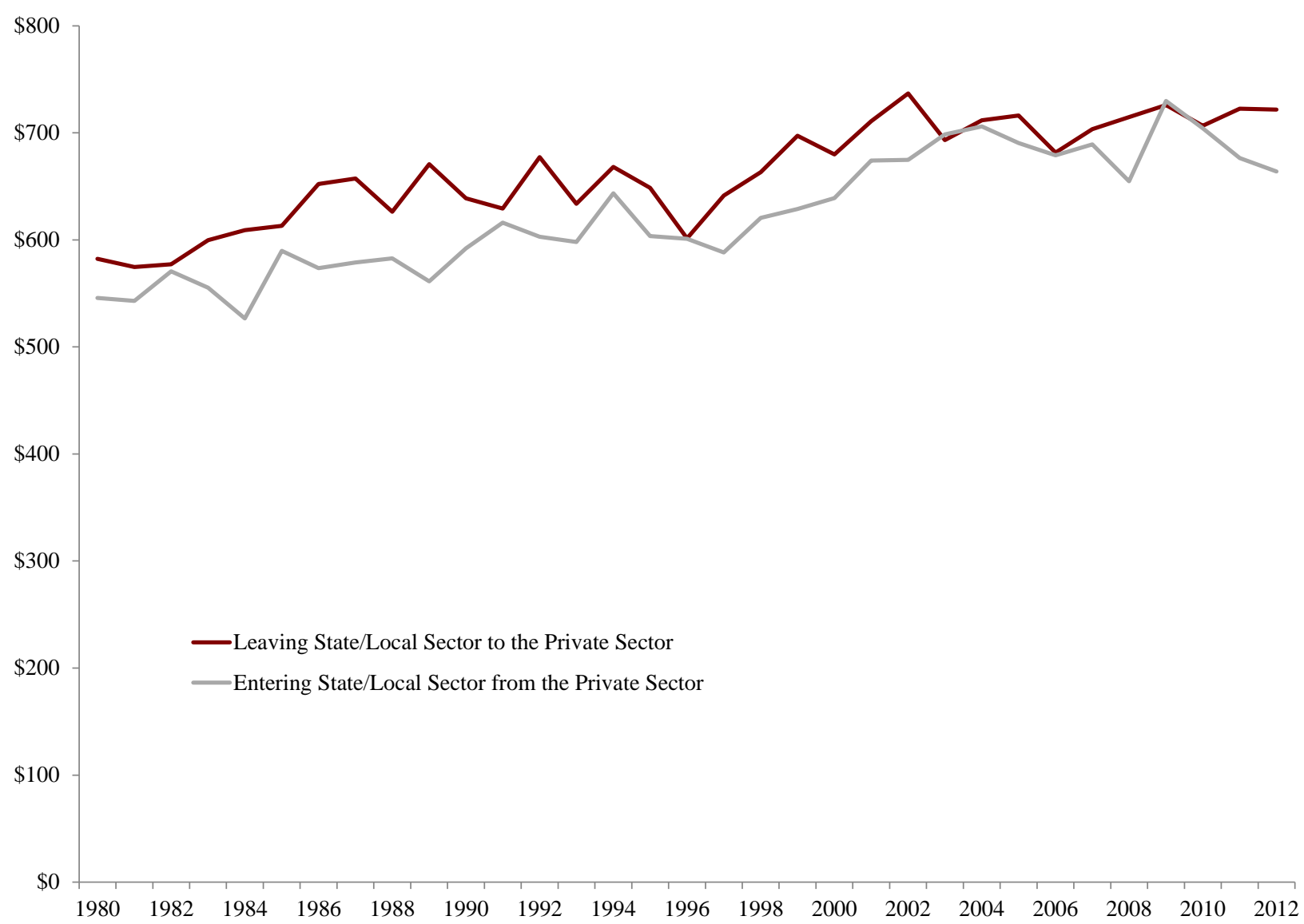

Note: Wages are normalized to year 2000 dollars. The analysis only includes workers aged 18-64 who were either: 1) working in the private sector at time $t$ and the state/local sector at time $t+1$ (entering state/local); or 2) working in the private sector at time $t$ and the state/local sector at time t-1 (leaving state/local). The analysis excludes workers working fewer than 35 hours per week in either year as well as workers making fewer than 90 dollars per week in either year.

Source: U.S. Census Bureau and National Bureau of Economic Research, Current Population Survey Outgoing Rotation Groups, 1979-2013. 
Figure 1B. Average Real Private sector Weekly Earnings of Full-Time Workers Entering and Leaving the Private Sector, 1980-2012

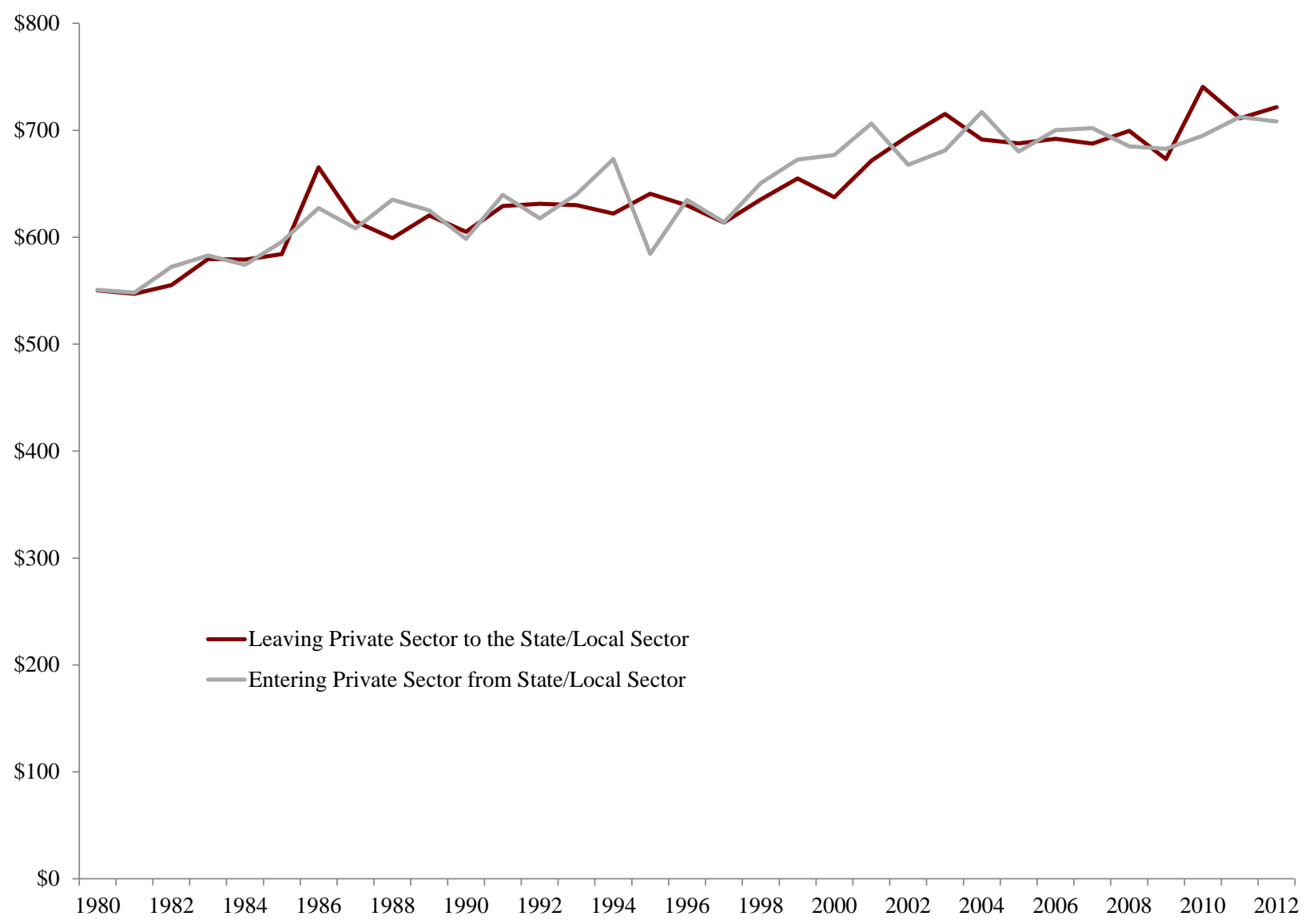

Note: Wages are normalized to year 2000 dollars. The analysis only includes workers aged 18-64 who were either: 1) working in the state/local sector at time $t$ and the private sector at time $t+1$ (leaving private); or 2) working in the state/local sector at time $\mathrm{t}$ and the private sector at time $\mathrm{t}-1$ (entering state/local). The analysis excludes workers working fewer than 35 hours per week in either year as well as workers making fewer than 90 dollars per week in either year.

Source: U.S. Census Bureau and National Bureau of Economic Research, Current Population Survey Outgoing Rotation Groups, 1979-2013. 


\section{RECENT WORKING PAPERS FROM THE CENTER FOR RETIREMENT RESEARCH AT BOSTON COLLEGE}

Do Tax Incentives Increase 401(k) Retirement Saving? Evidence from the Adoption of Catch-Up Contributions

Matthew S. Rutledge, April Yanyuan Wu, and Francis M. Vitagliano, November 2014

Are Retirees Falling Short? Reconciling the Conflicting Evidence

Alicia H. Munnell, Matthew S. Rutledge, and Anthony Webb, November 2014

Lifetime Job Demands, Work Capacity at Older Ages, and Social Security Benefit Claiming Decisions

Lauren Hersch Nicholas, November 2014

Who Is Internationally Diversified? Evidence from $296401(\mathrm{k})$ Plans

Geert Bekaert, Kenton Hoyem, Wei-Yin Hu, and Enrichetta Ravina, November 2014

The Causes and Consequences of Financial Fraud Among Older Americans

Keith Jacks Gamble, Patricia Boyle, Lei Yu, and David Bennett, November 2014

New Evidence on the Risk of Requiring Long-Term Care

Leora Friedberg, Wenliang Hou, Wei Sun, Anthony Webb, and Zhenyu Li, November 2014

SSI at 62: Protecting the Vulnerable When Increasing Social Security's Early Entitlement Age

Norma B. Coe and April Yanyuan Wu, June 2014

Why Do SSI and SNAP Enrollments Rise in Good Economic Times and Bad?

Matthew S. Rutledge and April Yanyuan Wu, June 2014

The Impact of Mandatory Coverage on State and Local Budgets

Alicia H. Munnell, Jean-Pierre Aubry, and Anek Belbase, May 2014

Interest Rates and Economic Growth: Are They Related?

Barry P. Bosworth, May 2014

The Tradeoff Between Health and Wealth in Retirement Decisions

Kristine M. Brown, May 2014

The Effect of Increasing Earnings Dispersion on Social Security Payroll Tax Receipts

Richard Kopcke, Zhenyu Li, and Anthony Webb, May 2014

All working papers are available on the Center for Retirement Research website

(http://crr.bc.edu) and can be requested by e-mail (crr@bc.edu) or phone (617-552-1762). 